\title{
Por uma história do pensamento sobre o fazer da iluminação cênica moderna: a cena além do humano ${ }^{1}$
}

For a history of thinking about making of modern stage lighting: the stage beyond human

Berilo Luigi Deiró Nosella ${ }^{2}$ 


\section{Resumo}

O presente artigo, um dos resultados parciais de pesquisa de pós-doutoramento sobre uma história do fazer e do pensamento da iluminação cênica moderna, apresenta algumas questões relativas a tal proposição e estabelece algumas bases do pensamento da iluminação em cena entre finais do século XIX e início do XX. Para tal, articula, com base sobretudo em Adolphe Appia e Gordon Craig, a relação entre os avanços propiciados pela iluminação elétrica e reconfigurações das tradições do teatro de figuras (marionetes), como estudado por Cristina Grazioli, numa proposição de modernização da cena, considerando-se os modos de produção, tanto da iluminação quanto da cena, em seus contextos culturais.

Palavras-chave: História da iluminação cênica; história e historiografia do teatro; teatro de formas animadas; Adolphe Appia; Gordon Craig

\section{Abstract}

This paper, as one of the partial results of post-doctorate research on a history of making and thinking of modern stage lighting, in addition to present some issues regarding such propositions, aims to establish some thinking groundwork of stage lighting between the end of the 19th century and the beginning of the 20th century. For this purpose, it articulates, especially in the thinking of Adolphe Appia and Gordon Craig, the relation between advances provided by electric lighting and reconfigurations of puppet theater traditions, as studied by Cristina Grazioli, in a proposition of stage modernization, considering the production ways, either lighting and stage, in their cultural contexts.

Keywords: Theater history and historiography; stage lighting history; puppet features theater; Adolphe Appia; Gordon Craig

\footnotetext{
${ }^{1} \mathrm{O}$ presente artigo é resultado parcial da pesquisa "Capocomicato e metateatro: o fazer e o pensamento da iluminação na dramaturgia pirandelliana", desenvolvida como parte do estágio pós-doutoral, em realização, de agosto de 2017 a julho de 2018, junto à linha de pesquisa em História e Historiografia do Teatro e das Artes do Programa de Pós-graduação em Artes Cênicas da Universidade Federal do Estado do Rio de Janeiro (UNIRIO), sob supervisão da profa. dra. Maria de Lourdes Rabetti (Beti Rabetti), com financiamento da Coordenação de Aperfeiçoamento de Pessoal de Nível Superior - CAPES

${ }^{2}$ Prof. Dr. do Curso de Graduação em Teatro e do Programa de Pós-graduação em Artes Cênicas do Departamento de Letras, Artes e Cultura da Universidade Federal de São João del Rei. berilonosella@ufsj.edu.br
} 
Dá-nos luz no palco, eletricista! Como podemos nós

Autores de peças e actores apresentar na meia-luz As nossas imagens do mundo? A penumbra nebulosa

Faz adormecer.

(Brecht, 1999, p. 165)

Mas quem garante que a luz é melhor que as trevas? No escuro eu penso melhor. (Alberto Savinio, apud Grazioli, 2015, p. 186)

\section{Questões introdutórias}

No Brasil, os estudos sobre iluminação cênica ainda são poucos, embora venham ganhando espaço e consistência nos meios acadêmicos e já apresentem resultados incisivos na produção atual desse segmento. Destacam-se os casos recentes da tese defendida por Eduardo Tudella (2013) na UFBA - Práxis cênica como articulação de visualidade: a luz na gênese do espetáculo ${ }^{3}$ - e o extenso trabalho integrando dissertação e tese sobre a linguagem da iluminação cênica moderna empreendido por Cibele Forjaz Simões $(2008,2013)$ na USP - À luz da linguagem: a iluminação cênica: de instrumento da visibilidade à 'scriptura do visível', além da precursora dissertação de Hamilton Saraiva (1989), Iluminação teatral: história, estética e técnica, e sua tese de doutorado, Interações físicas e psíquicas geradas pelas cores na iluminação teatral (Saraiva, 1999). ${ }^{4}$ Porém, o foco sobre a história da cena tendo a iluminação como objeto ainda é campo pouco explorado não apenas na universidade brasileira, mas na academia de forma geral. Nesse campo e no interesse específico deste artigo, deve-se citar o trabalho da professora e pesquisadora Cristina Grazioli, da Universitá di Padova 5 .

O interesse particular pelo trabalho de Grazioli para o presente artigo decorre de seu olhar historiográfico e do possível paralelo entre a história e a prática da iluminação na cena moderna e as tradições e reflexões sobre o teatro de figuras, ou teatro de formas animadas, que, segundo a autora, deve ser entendido como aquele que leva em conta a "alma das coisas", pois, "as 'coisas' têm alma, mas somente o olhar e o movimento afetivo de quem com elas se relaciona é capaz de lhes dar vida" (Grazioli, 2016, p. 34). Tal relação - entre os avanços tecnológicos da iluminação no século XIX e um interesse particular pelas questões do teatro de figuras -, como germinadora de certa forma de conceber o teatro e a cena dos movimentos modernistas entre finais do século XIX e início do XX, nos parece singular e importante como dado para elaborar a base de uma possível história da iluminação moderna como história da cena e do teatro.

\footnotetext{
${ }^{3}$ Prêmio Capes de Tese em 2014 e publicado em livro pela editora da Universidade Federal da Bahia em 2017.

${ }^{4}$ Exatamente por ser ainda restrita a produção acadêmica na área, não se apresenta grande dificuldade ao pesquisador ou interessado em acessar o que existe publicado e divulgado sobre o assunto em nosso país. Indico a breve apresentação dessa produção, tanto nacional quanto estrangeira, em Tudella, 2013, p. 90-93 e Camargo, 2006, p. 27-50.

${ }^{5}$ Cristina Grazioli, uma das mais renomadas pesquisadoras da História da lluminação Teatral da atualidade, apresentou seus trabalhos sobre o tema no Brasil, inicialmente, no ano de 2015, quando realizou "aulas/conferências" sobre "Teorias e práticas da iluminação cênica", na Universidade Federal do Estado do Rio de Janeiro (UNIRIO), durante a $5^{\mathrm{a}}$ Missão de Trabalho do Acordo Internacional estabelecido entre aquela Universidade e a Università di Padova (UNIPD), missão de trabalho que, como outras do mesmo Acordo, estendeu-se a outras instituições, dentre as quais, a Universidade Federal de São João Del-Rei, quando tivemos oportunidade de conhecê-la pessoalmente.
} 
Nesse sentido, pensar uma história da iluminação cênica deve transcender apenas o olhar para seus resultados visuais, voltando-se também para o campo de sua produção artística, como linguagem em cena, mas também como desenvolvimento tecnológico fundamental na vida cotidiana das sociedades humanas. O olhar para o pensamento sobre a cena e sua iluminação atravessa os modos de fazer essa cena e sua luz, o que se insere diretamente no contexto dos modos de produção da cena. $A$ noção de "modo de produção teatral", desenvolvida por Maria de Lourdes Rabetti (Beti Rabetti) em sua trajetória de pesquisa, revela-se conceito fundamental para a presente proposta de possíveis bases para uma história da iluminação cênica. Tal conceito reafirma "a leitura de que o fazer teatral está sempre articulado às condições econômicas, políticas e sociais de produção" (Rabetti, 2005, p. 31), fundamental para o estudo da cena cuja materialidade abarca tanto os elementos estéticos culturais, plasmados em longa acumulação artística, como os contextos econômicos e políticos em que estão inseridos (Rabetti, 2007, p. 13-16). Nesse sentido, a noção de modo de produção da cena abrange a compreensão do estético de maneira ampla assimilando fundamentalmente seu fazer, sua técnica, inserida em um dado contexto histórico. No caso da iluminação cênica, desde finais do século XIX - com a invenção da lâmpada incandescente com haste de carvão (carbono) por Edson em 1879 - e ao longo de todo século $X X$, a conjunção de estética e modo de fazer é de impossível desmembramento; todos os grandes avanços estéticos estão relacionados ao desenvolvimento técnico, consequentemente, a avanços (ou retrocessos) políticos e econômicos. Já no presente exemplo da lâmpada de Edson, que muitas vezes é equivocadamente considerada o marco da "invenção da luz elétrica", isso se torna claro ao entendermos que sua importância histórica está no fato de que tal invenção, de forma mais precisa, foi o que permitiu economicamente a exploração e difusão da iluminação elétrica em grande escala pela indústria da época (Simões, 2008, p. 60). Assim, pensar uma história da iluminação em cena é pensar os modos de produção, ou seja, pensar o teatro inserido em dado contexto e com ele se articulando cenicamente.

É nesses sentidos que propomos, no presente artigo, um primeiro olhar para uma possível história da iluminação cênica moderna como uma história do pensamento da iluminação em cena, entendendo que o particular avanço tecnológico nesse campo, atrelado à valorização da luz como elemento da cena, proporciona uma visão em que os diversos elementos da cena ganham alma, reformulando, a partir de tradições e renovações, nossa própria compreensão do que seja a cena.

\section{História da iluminação, história do teatro, história da cultura}

Talvez a primeira premissa para o percurso que estamos propondo seja entender que uma história do teatro não é única, mas feita de conjuntos de histórias, com diversas temporalidades e regionalidades, para além apenas de diversos objetos. Dessa complexidade e das relações entre essas diversas histórias é que podemos inferir uma história do teatro e cada vez mais construir versões pertinentes dela. Não se trata apenas da história da cena, do texto dramático ou da atuação; tampouco dos elementos como cenário, figurino, iluminação, etc.; trata-se também das histórias da arquitetura e da urbanidade, da literatura, do corpo, da visualidade, etc. e, considerando as dimensões do fazer humano, da história das sociedades e das culturas. 
O que queremos dizer é que, pensar uma história da iluminação cênica é (ou deveria ser) sempre pensar uma história do teatro e vice-versa; assim como também é (ou deveria ser) pensar uma história da tecnologia e da indústria, em se tratando da iluminação cênica moderna. Isso implica, primeiramente, o fato de que pensar uma história da iluminação cênica significa o enfrentamento rigoroso das mesmas questões historiográficas e metodológicas envolvidas nos diversos estudos históricos - com suas particularidades, naturalmente, como em qualquer campo dos estudos históricos, mas com bases conceituais e metodológicas (aparentemente) fora do campo da prática de nosso objeto de estudos.

No campo específico, como apontado, há o conhecimento (tanto adquirido quanto a ser desenvolvido) de um rol de questões, práticas e materiais, que dizem respeito ao fazer da iluminação em geral e seus processos de incorporação e aplicação em cena; pressupondo, entretanto, termos o conhecimento de que grande parte da tecnologia utilizada em cena, em diversos momentos da história e não apenas hoje, não foi desenvolvida para esse fim específico. Há ainda o conhecimento acumulado em torno do que chamamos de história do teatro, ou histórias do teatro, também permeado pelo saber do fazer. Nesses contextos, o papel da investigação histórica entrelaça-se e apresenta aprofundamentos e ganhos que, longe de constituir um "acúmulo de velharias" e mesmo ao contrário disso, dialogam constantemente com trajetórias do saber fazer que se vertem no presente. Como afirma Grazioli (2016, p. 29), "o historiador do teatro precisa sempre adotar um olhar 'estrábico', com um olho fixado no objeto de estudo e sua época e o outro no presente", pois é para o presente que convergem os olhares tanto do artista quanto do historiador. Assim, trabalhar com o passado, no campo da história do teatro (e talvez de toda história), é um imbricado trabalho interdisciplinar entre o próprio olhar (historiográfico), o objeto específico (no caso o teatro ou a iluminação cênica) e seus diversos e dependentes conhecimentos.

Ao olhar para o objeto específico, considerando sua temporalidade passada, o historiador do teatro preocupado com a iluminação cênica precisa, segundo Grazioli (2016, p. 24), "armar-se de lentes para interrogar as fontes":

Para trabalhar com os fenômenos dos séculos passados, são necessários a contex-
tualização e o emprego dos instrumentos críticos e metodológicos da teatrologia.
É desejável fazer com que a história fale com a voz do presente, mas, assim como
outra disciplina qualquer, a "ciência do teatro" impõe, além dos instrumentos
que se revelarão necessários para cada objeto de estudo, uma série de critérios
inevitáveis: fundamentalmente, a leitura das fontes (direta, se possível) e sua con-
fiabilidade, coerência hermenêutica, competências específicas do contexto histó-
rico-cultural, muita cautela no uso de fontes iconográficas, coisas óbvias para um
estudioso, mas não necessariamente para um crítico e muito menos - justamente
- para um artista que pode utilizar a pesquisa histórica como fonte de inspiração
criativa. (Grazioli, 2016, p. 24-25)

Afinal, é no olhar do historiador para a fonte que o conhecimento se gesta, o que equivale a dizer que tal olhar é prática de ofício, e o ofício é o que define o historiador. É nesse trabalho meticuloso e, como já dito, metodologicamente rigoroso, que a ponte entre história e arte teatral, como a que estamos pensando, pode realizar-se sem concessões aos objetivos próprios do fazer e da criação teatral, mas sem deles 
se afastar. Em meio às materialidades diversas do fato e do documento, da fonte e das interpretações, o historiador estabelece um trabalho de cunho analítico que não pode prescindir de alguma noção de construção incluindo um rol de conhecimentos e competências que, sem ferir o documento, estão fora dele e de seu campo, muitas vezes mais ligados a seus objetivos; concomitantemente, ele não pode prescindir dos conhecimentos que estão diretamente contidos no documento e são oriundos da prática que o gesta. ${ }^{6}$ Isso estabelece um jogo entre fato e documento que as competências do historiador, necessariamente não restritas, devem destrinchar na construção histórica. No caso de uma história da iluminação, ao nos apresentar como o fato do apagar da plateia no século XIX possui em diferentes casos proposições, significados e consequências profundamente diversas, Grazioli (2015, p. 151) chama atenção para como "em matéria de luminotécnica as soluções individualmente avaliadas, fora de seus contextos, não ajudam a entender seus significados"; 7 a não compreensão dos mecanismos luminotécnicos que possibilitaram tal apagamento, entretanto, também impedem a compreensão do fenômeno.

Tal particularidade se apresenta, dependendo do campo, e é o caso do nosso em específico, nos tipos de documentos e nos necessários tratamentos que eles exigem; assim, a forma de trabalhar analiticamente com os documentos se faz aspecto fundamental. As questões que mais nos interessam numa proposta de história da iluminação cênica, no campo metodológico, ligam-se intimamente a suas limitações documentais, quando precisamos lidar com documentos particulares. São poucos e raros, por diversas razões que aqui não cabe tratar, os documentos diretamente oriundos da prática da iluminação cênica, e, quando existem, são muitas vezes considerados de outro campo de conhecimento e não da cena, demandando, como afirmamos, abordagens e conhecimentos específicos; porém, reiteramos, munidos apenas desses conhecimentos específicos, podem nos escapar contextos importantes em sua compreensão. É nesse jogo entre conhecimento específico do objeto e conhecimento histórico e historiográfico que uma história da iluminação se faz possível.

Novamente Grazioli (2016, p. 26-27) indica um caminho pertinente, ainda que se referindo a uma proposta de história do teatro de figuras: "Se houver pouco material conservado, o estudioso pode se valer de roteiros e enredos (quando previstos nos gêneros)", fornecendo a pista da possibilidade de uso da dramaturgia como fonte primária de análise historiográfica do pensamento da iluminação em cena. Ao menos por enquanto, podemos afirmar isso no caso do teatro moderno, uma vez que, segundo Grazioli (2016, p. 31-32), a modernidade, entre finais do século XIX e início do $X X$, se apresenta como um "elo" entre tradição e contemporaneidade:

Um momento que deve ser visto isoladamente no nosso discurso é aquele que definimos como o "elo" entre tradição e contemporaneidade. O grande laboratório representado pelas artes do fim do século XIX e início do XX foi quem estabele-

\footnotetext{
${ }^{6}$ Por exemplo, um mapa de iluminação, criado com o objetivo de indicar tecnicamente como se realiza a luz de um espetáculo, utilizado como fonte, carrega em si informações técnicas cujo desconhecimento pode limitar sua leitura documental.

7 "In materia di illuminotecnica le soluzioni valutate singolarmente, tolte dal loro contesto, non aiutano a capirne il senso" (Todas as traduções do italiano para o português deste artigo são de minha autoria).
} 
ceu as premissas, não somente artísticas, mas também histórico-críticas, estéticas e hermenêuticas para os nossos estudos atuais. As formulações teóricas dos grandes reformadores da "concepção" da Marionete (Maeterlinck e Craig, para citar dois nomes inesquecíveis, mas poderíamos mencionar tantos outros) representam a passagem através da qual despontam todas as propostas das Vanguardas.

A relação entre as transformações propiciadas pela iluminação elétrica e possíveis releituras das tradições do teatro de figuras, num questionamento sobre a própria relação de ficção e realidade, influirá diretamente na mentalidade e compreensão visual dos artistas da cena, entre eles os próprios dramaturgos, a ponto de promover uma rearticulação da maneira de conceber a escrita para cena, plasmada em textos com latente metalinguagem (Nosella, 2014):

[...] destacam-se as mudanças na concepção de dramaturgia e, sobretudo, do personagem. Pode-se partir da análise de textos que não constroem mais o personagem do modo tradicional, ler Beckett ou Pirandello como articulações-chave desses deslocamentos. Ver Einstein on the beach para compreender o que significa a relação entre os sinais visuais e sonoros da escrita cênica, propor o Teatro de Sombras contemporâneo como demonstração da multiplicidade das relações entre ator e personagem e do valor dramatúrgico dos dispositivos cênicos, e assim por diante. (Grazioli, 2016, p. 31)

Sendo assim, é para esse contexto do teatro moderno que voltaremos nosso olhar a fim de pensar, como já dissemos, algumas questões iniciais para o que pretendemos como uma história da iluminação moderna, ou, mais precisamente, uma história do pensamento da iluminação cênica moderna. Embora não sendo ainda aqui que iremos empreender o exercício analítico da dramaturgia (como elemento pré-cênico) como documento para a história de nosso interesse, procuraremos, num olhar para o final do século XIX e início do XX, estabelecer certas bases da história que temos em mente, esperando que, como proposição, estas linhas possam, contraditoriamente, lançar luz sobre uma prática muitas vezes obscurecida.

\section{Por uma história do pensamento da iluminação em cena}

O teatro moderno, abalizado pelo dito "surgimento do encenador" e pela invenção da iluminação elétrica, ${ }^{8}$ localizado entre finais do século XIX e início do XX, se encontra marcado pela dualidade, expressa em seu maior antagonismo, nos dois movimentos estéticos de sua gestação: o naturalismo e o simbolismo (Roubine, 1998, p. 19-44). Argumentamos que tal dualidade não é tão antitética, mas com certeza abriga elementos fundamentais à compreensão do período. ${ }^{9}$ No que tange à iluminação, tal dicotomia se apresenta naquilo que consideramos o fundamento

\footnotetext{
${ }^{8} E$ í importante esclarecer, mesmo que apenas de forma pontual, que a referida invenção da iluminação elétrica constitui um processo histórico de inúmeras invenções e descobertas do final do século XVIII ao início do XX. Para uma ideia desse processo, ver Grazioli, 2015.

${ }^{9}$ É valiosa a leitura de Bernard Dort (1977, p. 49) sobre o naturalismo mostrando que "Pretender instalar o real no palco não é instituir uma falaciosa e impossível identidade entre teatro e realidade: é colocar totalmente em questão a atividade teatral. [...]. É passar da imitação ideal da natureza à criação de uma nova natureza, através dos meios específicos da expressão teatral. Por um singular paradoxo, o ilusionismo naturalista cedo se transforma em seu contrário: a recusa de toda a ilusão, de toda a reprodução do real".
} 
de como será pensada a iluminação cênica até nossos dias: a dualidade de luz para ver e para expressar.

Não apenas num campo de debate estético, tal dualidade carrega em si a essência de qual é ou quais são as funções primordiais da iluminação cênica, que, de acordo com Tudella (2013, p. 32), se dividem, sem ser distintas, em visibilidade e visualidade. Sem luz não há visão; essa máxima física e biológica define a priori uma das funções primordiais da iluminação: fazer ver. Se pensarmos que já em seu nome (Theatron, lugar de onde se vê ou para ver) a arte teatral pressupõe a visão, a relação entre a essencialidade da luz para a arte da cena é imediata. ${ }^{10}$ Nesse âmbito, a visibilidade, que podemos considerar o processo de sensibilização do aparelho óptico humano pela luz refletida em um objeto, gerando a visão, é a primeira função da iluminação cênica. Como diria Craig (2017, p. 225),

Ao criar uma cena para um drama que valha ser ouvido e valha ser visto, não podemos nunca esquecer o que os espectadores demandam.

Uma das primeiras exigências é que eles sejam capazes de ver e ouvir os atores à medida que encenam diante de nós, especialmente seu rosto (ou máscara) - e suas mãos e pessoa.

Tornar algo visível, para além do elemento técnico mais primário - a luz incide sobre um objeto, é por ele refletida, captada por nosso olho e decodificada por nosso cérebro -, instaura, porém, um regime de visão específico, pois não só vemos, como vemos de uma determinada forma. Essa "determinada forma" podemos chamar de visualidade, ou seja, como se vê um determinado objeto iluminado por uma determinada luz. Nesse campo, imbricam-se duas questões: a primeira diz respeito ao modo como o objeto é iluminado; não basta dizermos que na incidência de luz ele se torna visível, pois como ele será visto dependerá da intensidade, do ângulo, da característica dessa incidência, além da cor e sua complexa relação com as capacidades reflexivas do objeto em si; a segunda trata da maneira como a luz codificada por nosso cérebro e tornada visão é "lida" pelo filtro da cultura. Assim, no processo de visão se encontram sobrepostos estas duas funções, visibilidade e visualidade, e para nós é importante entender que ambas conjugam um único fenômeno, que chamamos de visão. Citando Hal Foster, Tudella (2013 p. 52) afirma: "Embora o termo visão sugira o ato de ver como uma operação física, e visualidade como um fato social, os dois não se opõem, como aspectos da natureza, à cultura: a visão é social e também histórica, e a visualidade envolve o corpo e a mente".

Voltando ao teatro moderno, Bablet (1964 p. 294) afirma essa dualidade de funções da luz ao informar sobre os primeiros anos da incorporação da iluminação elétrica pelos teatros:

A luz não é, pois, senão um meio técnico de reproduzir "fielmente" o lugar dramático. Não desempenha qualquer papel activo na valorização do drama, não

\footnotetext{
${ }^{10}$ Tal premissa visual, acreditamos, permanece válida mesmo numa cena em que haja total ausência de luz, pois o black-out (termo técnico para a ausência deliberada de luz na cena), na própria característica visual do fenômeno, instaura uma circunstância cênica em que a ausência da visão cria também relações visuais, sejam sensoriais e/ou sígnicas.

${ }^{11}$ Cibele Forjaz Simões (2008, p. 116), em sua dissertação de mestrado, desenvolve a comparação, com a qual concordamos, entre luz passiva e o que bem conhecemos na prática da iluminação cênica ainda em nossos dias como luz geral; e luz ativa com a ideia de luz de efeito.
} 
intervém na acção. O quadro cénico só tem uma função descritiva, é um fundo visual, o resultado de uma série de compromissos que se baseiam num acordo instável: luz e cenário pintado. A luz é passiva.

E, ao fazê-lo, apresenta a designação dada por Appia às duas funções básicas da iluminação, que nos servirão de apoio para pensar a prática e o pensamento referentes à iluminação cênica no século XX, quiçá até nossos dias - as noções de luz passiva e luz ativa ${ }^{11}$ ou, poderíamos dizer, "luz que 'ilumina' e luz 'criativa'" (Grazioli, 2015, p. 155). ${ }^{12}$ Já adiantando, porém, que cada uma se relaciona com as funções já apresentadas de visibilidade e visualidade e, portanto, como essas, não devem ser pensadas de forma tão radicalmente oposta, como nos parece propor Bablet.

Sintetizando para dar continuidade e atendendo à funcionalidade da visibilidade, a luz passiva seria aquela que tem por objetivo tornar visível o espaço da cena e tudo que ele contém; enquanto a luz ativa é a responsável por "ativar" a vida potente do próprio espaço, por seu movimento em cena, sua cor, por seu contraste com a sombra, sempre em relação com o espaço, seus objetos, atores, etc.; ela, portanto, age no espaço no sentido de determinar como ele é visto mais do que de apenas torná-lo visível, atendendo à funcionalidade da visualidade.

Appia concebe determinados aparelhos com características próprias para realização de cada luz. A luz passiva deve realizar sua função de iluminar da forma mais neutra possível, o que significa interferir o mínimo no espaço no que tange à cor e ao contraste; deve, portanto, ser branca e a mais difusa ou suave possível, realizada com refletores abertos e fixos. A luz ativa deve ser direta, ou dura, provocando contraste e intervindo na cor; deve ser realizada com refletores pontuais e móveis (Grazioli, 2015, p 154). No caso da luz passiva, Appia, tendo insistido em afirmar que ela se deve integrar o máximo possível ao espaço, atingiu a radicalidade desse conceito ao projetar a "sala de apresentações" do Instituto Jacques Dalcroze. ${ }^{13}$

A iluminação desta sala, realizada por Alexandre von Salzmann coloca em prática a ideia da geral de Luz Difusa, a partir das concepções de Appia e da experiência prática de Mariano Fortuny com sua cúpula de reflexão, ${ }^{14}$ [...]. Porém, o projeto final se parece mais com as propostas de Appia em "A música e a encenação", porque as luzes são difundidas não através de rebatimento, mas de grandes telas "difusoras" que escondem as fontes de luz dispostas no teto e paredes do espaço. Um projeto de luz engenhoso e com efeito surpreendente. (Simões, 2008, p. 127)

Essa proposta de um "espaço de luz" realizando a função da luz passiva, buscando sua máxima neutralidade, existe exatamente para que a função da luz ativa seja preservada de maneira radical. É essa correlação entre os dois tipos de luz em suas funções específicas o que promove a existência de uma luz viva no espetáculo, como Appia (s.d.) propõe em A obra de arte viva, publicada originalmente em 1921. Uma luz que seja essencialmente movimento, capaz de criar no espaço cênico, no

\footnotetext{
${ }^{12}$ Luce "che rischiara" e luce "creatrice".

${ }^{13}$ A "sala de apresentações" do Instituto Jacques Dalcroze foi construída em Hellerau, Dresden, Alemanha, em 1911 pelo arquiteto Heinrich Tessenow, a partir das concepções de Appia e Dalcroze. (Simões, 2008, p. 126)

${ }_{14}$ Mariano Fortuny (1871-1949) foi construtor e inventor, cenógrafo, arquiteto, pintor e iluminador; das várias invenções de aparelhos de efeitos para cena, a mais célebre foi a "Cúpula Fortuny", de 1902. "Em 1902 o cenógrafo Mariano Fortuny desenvolve, na Alemanha, o 'kuppelhorizont', uma meia-cúpula feita de seda ou gesso, que refletia luz sobre o palco, simulando o infinito (céu). Este recurso daria origem ao ciclorama, tela semicircular, no fundo do palco, iluminada geralmente do topo e da base, empregada para efeitos de céu". (Camargo, 2012, p. 18)
} 
jogo com o corpo do ator em movimento, ao atuar em todo espaço, interligando-o, uma "obra de arte viva", que seria uma obra que congrega em sua essência tempo e espaço (Appia, s.d.).

Tal correlação entre luz passiva e luz ativa, que espelha a correlação entre visibilidade e visualidade, é a matéria fundamental do trabalho de encenação e do iluminador, pois toda visibilidade pressupõe uma visualidade, posto que mesmo a luz passiva possui movimento. Se há visualidade já como essência de todo fenômeno cênico - incluindo os que poderíamos chamar de pré-cênicos, como a dramaturgia, por exemplo -, neles está presente um potencial de visualidade, que é o espaço de atuação da encenação.

A luz que podia ser identificada em momentos anteriores à estreia de um espetáculo, também se manifestou antes que a ideia de cena alcançasse as salas de ensaio. Ela já estava presente nos traços do espetáculo e pulsava no trabalho do dramaturgo, caracterizando uma espécie de estado "pré-cênico", um processo vivo, constituído por todas as atividades que ocorrem desde as primeiras ideias que levam à realização espetacular. Transformando-se sucessivamente, o estado pré-cênico encerra-se quando o acontecimento teatral ocorre efetivamente diante do público. O que parece óbvio, mas não equivale a dizer que o diretor ou o encenador está obrigado a usar o texto como um livro de regras. (Tudella, 2013, p. 28)

O que chamamos aqui de material ou estado "pré-cênico" produz uma espécie de campo intra-visível ou intra-visual, possível de ser acessado pela imaginação criativa, a ser concretizada numa opção de visualidade pelo espetáculo, ao torná-lo externamente visível.

Essa abordagem incorpora à aplicação da luz na obra artística a compreensão de componentes intra-visíveis. A interação entre visibilidade e visualidade revela uma categoria intra-visivel presente nos pressupostos estético-poéticos alocados no interior de uma obra, e.g., o acontecimento espetacular, e que permaneceriam desconhecidos [in-visiveís] numa hipotética exclusiva aplicação de visibilidade. Como já foi dito, a resposta do iluminador às atmosferas presentes na ideia primeva de cena inclui aspectos artísticos, exigindo a aplicação de conceitos ligados ao discurso visual, como cor, textura, forma, intensidade, ritmo, movimento, equilíbrio, força, entre outros. (Tudella, 2013, p. 54)

Nesse jogo criativo, com a intenção, como já dito, de produzir a luz viva, portadora e geradora de integração e movimento em cena, tornando vivos a cena e o corpo do ator, Appia estende o lugar de essência da cena, geralmente reservado ao corpo do ator, também à luz; o que a coloca numa espécie de centralidade cênica, objeto de nosso interesse no próximo tópico: a luz como elemento articulador e personagem da cena.

\section{A cena se anima: a luz como personagem}

Edward Gordon Craig, nascido em Stevenage, Inglaterra, em 16 de janeiro de 1872, e falecido em Vence, França, em 29 de julho de 1966, foi um dos mais importantes homens de teatro do período em que estamos transitando. Em 1905 edita seu

\footnotetext{
${ }^{15}$ Estamos nos referindo a esse como último dos três maiores ensaios de Craig sobre sua proposição de uma "cena do futuro", e não como sua última produção no campo teórico ou ensaístico. Para breve introdução à obra de Craig e ao ensaio em destaque, ver Ramos, 2017, p. 11-32.
} 
principal livro, Da a arte do teatro (1963), em que apresenta de forma extensa e pormenorizada suas principais ideias para a renovação da cena que propunha. Em 1913, dando continuidade à reflexão, publica Rumo a um novo teatro e, em 1922, Cena, ambos recentemente editados no Brasil (Craig, 2017). Para a discussão que queremos focar aqui, nos centraremos no último ensaio, ${ }^{15}$ fundamentalmente por três razões: 1) por considerar que, sendo o último ensaio, é aquele em que as ideias se encontrariam de forma mais "amadurecidas"; 2) por ser um ensaio em que, como o título já indica, ele se debruçará especificamente sobre as questões da conceituação e realização de sua proposição de cena, tendo a iluminação como fator central; 3) por ter sido escrito num momento importante em relação aos períodos de produção dos outros dois ensaios, marcado pela experiência da Primeira Guerra Mundial - muito fortemente vivida por Craig na Itália, tendo the provocado inúmeras dificuldades econômicas e sociais - e por seu contato com o teatro de bonecos italiano, principalmente a tradição dos buratiini'í (Ramos, 2017, p. 21).

Iniciando o texto, Craig já afirma certa proposição de que a cena deve ser um "lugar", ou seja, deve ser um espaço com vida e materialidade próprias, encontrando a unidade perdida entre o fenômeno cênico e a arquitetura, que envolveria todos os seus elementos, o público entre eles. Nesse contexto o autor propõe uma narrativa histórica da cena em quatro momentos: clássico (grego e romano), medieval (cristão), Italiano (commedia dell'arte) e um quarto, que ele não nomeia, mas se trata do período em que, durante o Renascimento e até finais do século XIX, os espetáculos são abrigados em edifícios fechados e próprios para a prática teatral. O quinto momento seria exatamente a renovação que Craig propõe como "Teatro do Futuro". O que ele demonstra é que em toda essa trajetória existe uma integração entre cena e arquitetura, num projeto que transcende a cena como espaço ficcional do espetáculo, algo como um espaço de convivência social amplo. É possível verificar isso em vários momentos do seu texto, incluindo o relato narrativo em que Craig conta como um suposto duque teria providenciado um espaço novo e propício à realização do fenômeno cênico. Tal passagem, mesmo que não apresente grande significação para a abordagem que escolhemos para o presente artigo, nas limitações que o gênero oferece, é digna de nota, uma vez que ali Craig apresenta a profunda relação entre esse projeto ampliado de cena e seu momento histórico político. No caso, o teatro, arquitetura como cena ampliada, é concebido a partir das bases da perspectiva, e Craig mostra como tal base tem como princípio a autoridade, personificada no duque, e plasmada num edifício que tem seu eixo central na visão do duque - a linha que define uma visão perfeita da perspectiva se estabelece entre o camarote real e a cena (Craig, 2017, p. 194-201).

Vejamos como ilustração, até de sua poeticidade, por exemplo, como ele descreve o teatro clássico, grego e romano:

Assim, então, a cena desses primeiros dramas era encenada ao ar livre.

Feita daquela matéria firme que, sozinha, é capaz de competir vitoriosamente ${ }^{16}$ Buratiini ou burattini são bonecos cujas mãos e cabeça são confeccionadas em madeira e interligadas por tecido que forma a roupa. Os manipuladores pratica-
mente os vestem como luvas, para lhes dar movimento. 
com o sol, o vento, a chuva, e contra o tempo... a pedra.

$\mathrm{O}$ teatro inteiro era feito de pedra - o teatro inteiro era a cena.

Uma parte dele abrigava os espectadores; a outra, atores; mas tudo isso era cena - o lugar para o drama. (Craig, 2017, p. 189)

Essa unidade perdida é o que Craig está buscando reencontrar, e para isso precisa desenvolver para a cena uma forma específica, carregada de simplicidade, ${ }^{17}$ de relação entre os diversos elementos que a compõem e, assim como Appia (s.d., p. 31), é o movimento não como elemento, mas como "a mobilidade, um estado, uma maneira de ser", que Craig também encontra. Sua nova cena é o que ele define como um teatro cinético-visual, tendo a luz e suas propriedades de energia - que viaja pelo espaço - e a cor como "o meio de regência dos vários elementos cênicos, [a luz] é elemento-chave para se chegar à concepção teatral de Edward Gordon Craig" (Grazioli, 2015, p. 157). ${ }^{18}$ Nessa busca, Craig (2017) chega a sua proposição dos screens, debatida e apresentada no texto Cena.

Screens eram telas e/ou biombos apoiados em rodinhas e, portanto, móveis, que podiam ser dispostos no palco conforme fosse predefinido pelo projeto de encenação. Tais biombos seriam movimentados por operadores efetivamente em cena, que, depois de ensaiados, "atuariam" movendo-os no que, aos olhos do público, seria uma espécie de dança. Uma vez posicionados, eles serviriam de suporte para que os demais elementos, fundamentalmente luz e atores, criassem um espaço expressivo de altíssima intensidade. ${ }^{19}$

Parece-nos importante, aqui, salientar que entre tal proposição de 1922 e suas versões pioneiras, de 1905, há uma reflexão sobre a técnica que evidencia uma espécie de recuo. Como o próprio Craig expressa em seu texto de 1922, o projeto dos screens se encontraria em estágio anterior ao de um máximo desenvolvimento tecnológico.

O mundo já usou canetas de bambu - depois canetas de pena - e depois canetas de aço. Estas eram molhadas em potes de tinta: muitas vezes um homem molharia a pena ali antes que pudesse escrever uma página de sua carta.

Alguém então inventou a caneta tinteiro. Um homem pode escrever toda a sua carta sem molhar a pena nenhuma vez em qualquer pote.

O mundo então inventou a máquina de escrever.

Eu compararia minha cena à caneta tinteiro e não às máquinas de escrever.

Não é um pedaço de mecanismo; é um dispositivo simples, formatado como telas - angular - liso. (Craig, 2017, p. 221)

Tal possível "recuo" tecnológico apresenta um quadro muito particular na proposição estética de Craig, uma vez que, nas primeiras proposições, constitui-se um rompimento maior com o drama e suas funções representacionais, enquanto a partir do recuo, há um retorno a essas funções. E o recuo não é apenas de âmbito estético,

\footnotetext{
${ }^{17}$ Assim, então, criar um espaço cênico simplificado é a primeira tarefa de um mestre do drama" (Craig, 2017, p. 211), sugere Craig ao artista responsável por realizar o teatro do futuro.

18 "[...] il mezzo di concertazione dei vari elementi scenici, è elemento chiave per accostarsi alla concezione teatrale di Edward Gordon Craig."

${ }^{19}$ Craig (2017) apresenta uma série de 19 gravuras em preto e branco (todas disponíveis em Cena) do que ele chama de "cena-mãe" de seu projeto.
} 
mas também funcional quanto à viabilidade do projeto, uma vez que, de 1910 a 1922 , Craig realiza suas patentes e procura vendê-lo enquanto proposta viável.

Ocorre que, se nas gravuras em metal de 1907 ele projetava essa cena quase etérea
e que pressupunha em espaço cênico liberto das funções representacionais, pronto
a expressar sentimentos e sensações abstratas como a música, no projeto que pa-
tenteou em 1910 suas pretensões artísticas se reduziram. Ali ele visava convencer
os produtores teatrais da época sobre um novo dispositivo, capaz de criar uma
"cena mutante", com muito menos elementos e com muito mais velocidade nas
variações, buscando assim, literalmente, vender sua ideia. Isso implicava em não
romper com o teatro dramático e, ao contrário, provar que seu dispositivo poderia
lidar com ele de modo muito mais efetivo e econômico. (Ramos, 2017, p. 28)

Uma das ideias que se encontra na base desse projeto, portanto, é a da capacidade de movimento e modificação da luz como essa energia que viaja e transforma nossa forma de perceber as coisas, fazendo lembrar o princípio de visualidade. Nesse contexto, mesmo sendo a iluminação elétrica uma nova tecnologia de ponta, ela traria à cena da época, e a Craig, a possibilidade de mutação quase infinita com custos mais baixos do que se dependesse da materialidade do cenário. E o referido baixo custo foi uma das grandes qualidades motivadoras da entrada da iluminação elétrica no palco. O baixo custo de manutenção, tanto do sistema de iluminação quando implementado quanto do próprio espaço de espetáculo, livre dos danos e incêndios promovidos pela iluminação a gás, foi o que motivou os donos de teatro e produtores a "impor" a nova tecnologia aos criadores, que a consideravam "muito clara", inviabilizando o lusco-fusco próprio da luz a gás, tão propício à criação de ilusões em cena (Grazioli, 2015, 130). Porém, contrariando a percepção desse momento de entrada da iluminação no palco, a cena moderna nos mostrará que o baixo custo não é sua única vantagem.

Numa série anterior, publicada em Rumo a um novo teatro, intitulada Steps (Degraus), Craig (2017, p. 104-113) mostra, a partir de quatro gravuras e suas descrições, como um mesmo espaço pode ser vários, expressando e imprimindo diversas sensações, por meio da interação espaço-ator-luz. Assim, os biombos seriam lisos e neutros (brancos), preparados para receber a luz que os modificaria, imprimindo no espaço a sensação desejada. Segundo o autor, com essa estrutura e o potencial transformador da interação espaço-ator-luz, seria possível atingir qualquer estado da alma, o que significaria ser possível expressar o "ambiente" interior de qualquer drama. É interessante aqui perceber como a cena, nessa proposição de relação espaço-ator-luz, se personifica para Craig ganhando status de persona.

Essa cena também tem o que eu chamo de um rosto. Esse rosto expressa. Seu formato recebe a luz e, à medida que a luz muda sua posição e fazem-se algumas outras mudanças, e considerando que a própria cena altera sua posição - os dois atuando em concerto como em um dueto, ambos revelando-a como em uma dança - até o ponto de expressar todas as emoções que eu quero que expresse. Sempre consciente de que, como um pano de fundo ao drama ou à atuação, só pode desempenhar seu ofício com discrição (e eu espero ser artista o suficiente para saber como fazer isso), enquanto mais uma vez pode avançar e atuar de algum modo em um papel mais proeminente. (Craig, 2017, p. 220) 
A cena em si ganha vida e assume expressividade própria. $O$ ator, na cena, e a personagem, no drama, deixam de ser o elemento central do teatro, e a cena, viva e com alma, em seu complexo de relações entre as vidas pulsantes que reúne (espaço - biombos manipulados por operadores à vista do público - atores - luz), assume essa centralidade. Não podemos afirmar que uma coisa seja estrita consequência da outra, mas podemos imaginar que o contato que Craig teve na Itália com diferentes manifestações tradicionais de teatro de bonecos ou marionetes possa ser uma das influências nessa visão de uma cena viva e da vida de seus elementos.

Eu vi, à medida que progredia, que as coisas podem, e consequentemente, deveriam desempenhar suas partes assim como as pessoas: que elas combinam com $\mathrm{o}$ ator e reclamam ao ator que as use, como as cadeiras nas peças de Molière $o$ confirmam. Não são meramente três ou quatro cadeiras mortas que ele colocou no centro do palco. Ainda que escritores nos convoquem a olhar o vazio de seu palco - apenas três cadeiras, eles dizem. Estão loucos, esses homens? Não percebem como Molière fez essas cadeiras atuarem - como elas estão vivas e trabalhando em combinação com os atores? (Craig, 2017, p. 210)

E tal visão é o que Grazioli (2016) aponta como sendo o grande legado de Craig para a cena moderna e contemporânea, como já apontamos, em sua concepção de marionete, que é revista, ampliada e lapidada no projeto dos screens, desde a publicação do ensaio "O ator e supermarionete", publicado em Da arte do teatro (Craig, 1963). Os desdobramentos de tal pensamento na própria modernidade são infindos; poderíamos dizer que, se o Renascimento foi o momento em que o homem foi posto no centro do mundo, entre o final do século XIX e início do século XX, com o avanço da Revolução Industrial e a mecanização do mundo, procura-se agora o além do humano ou, talvez, o não humano mais humano, antecipando as questões que serão aprofundadas no nosso tempo, por exemplo, com a inteligência artificial.

Dos diversos exemplos, como já dissemos infindos, que podem ser verificados desde os autômatos de Georg Büchner em Leonce e Lena, ${ }^{20}$ dos quais Grazioli (2015) em seu livro nos traz vários, sempre em sua relação com a luz, gostaríamos de citar o caso dos artistas futuristas. Para eles, a iluminação elétrica e suas potencialidades causam furor quanto a seus potenciais de movimento e avanço tecnológico. Não são poucos os exemplos do ânimo dos artistas futuristas com os desenvolvimentos tecnológicos da indústria - principalmente o motor, o automóvel - e suas comparações desses com animais vivos: "Um automóvel de corrida com o seu cofre enfeitado com tubos grossos, semelhantes a serpentes de hálito explosivo..." (Marinetti, s.d.).

No caso da iluminação elétrica, eles vão ainda mais além: "um dos seus mais notórios manifestos se intitula Nós matamos a luz da lua! e proclama o dogma da 'divindade luz elétrica', [...] todos os personagens são figuras-lâmpadas e dão luz à deusa"21 (Grazioli, 2015, p. 176). A autora apresenta alguns exemplos do que ela chama de

\footnotetext{
20 "VALÉRIO - Mas realmente eu gostaria de anunciar a esta subida e ilustre sociedade que aqui chegaram esses dois autômatos, mundialmente famosos, e que talvez eu seja o terceiro e o mais notável deles, se eu apenas soubesse efetivamente quem eu sou, coisa sobre a qual, aliás, ninguém deve se admirar, pois nem mesmo eu sei do que estou falando, e nem sequer sei que não sei, de modo que é altamente provável que só me deixam falar assim, e na realidade, são apenas tambores e flautas que dizem tudo. [...]". (Büchner, 2004, p. 224)

PETER (Colocando o dedo sobre o nariz.) - Em efígie? Em efígie? Presidente, quando se enforca alguém em efígie, isto não é a mesma coisa do que enforcá-lo de verdade?

PRESIDENTE - Com o perdão de Sua Majestade, isto é ainda muito melhor, pois não lhe sucederá nenhum mal e, apesar disso, será enforcado" (Büchner, 2004, p. 224-225).

${ }^{21}$ Uno dei loro più noti manifesti si intitola Uccidiamo il chiaro di luna! e proclama il dogma della "divina luce elettrica" [...] Tutti i personaggi sono figure-lampade e danno luce alla 'dea'.
} 
"dramas de objetos" (drammi d'oggetti) em que, por exemplo, uma lâmpada elétrica é personagem, ou que tem por personagem o Pôr do Sol, a Lua, o Lustre, a Lâmpada, a Vela, etc., ou até mesmo a Sombra, ausência de luz, assume a ação de figura em cena.

\section{Para concluir: uma cena que se aspira a mais que humana}

Uma proposição de história da iluminação, como já dissemos, não é única, mas nos parece que não pode (ou não deveria) ocorrer como algo separado de uma história do teatro. Na perspectiva do debate que aqui propusemos iniciar, enfocamos alguns aspectos de momentos formadores de um pensamento sobre a cena que teve a iluminação como um de seus animadores centrais. A modernidade, desde que o duque de Craig proporcionou um espaço fechado para a realização da prática teatral, vem acumulando conhecimentos e tecnologias que, em diálogo com o fazer teatral, nos proporcionaram grandes imagens. O período específico de finais do século XIX aos inícios do XX, um momento de radicalização dos processos de renovação tecnológica, trouxe consigo tanto transformações quanto promessas de transformações que animaram a imaginação dos homens das artes e das cenas, gestando o que hoje chamamos de teatro moderno.

As experiências da Revolução Francesa no raiar do século XIX e da Primeira Guerra Mundial no início do século XX, marcaram períodos de mudança na percepção e compreensão de nós mesmos e de nosso lugar no mundo, seja um lugar predefinido ao qual estamos sujeitos, seja um lugar novo a ser criado. Esses períodos, que carregam profundos traços de débito à tradição de nosso passado e radicais esperanças num novo futuro, não deixam de acreditar no humano, mas passam a criticá-lo e cobrá-lo por todo erro e mal que a história nos legou. Na instauração da dúvida no humano e suas certezas de superioridade diante da natureza, nos novos paradigmas instaurados pelo sujeito, sua individualidade e coletividade, na aproximação entre ficção e realidade num novo paradigma do conhecimento, o palco ou a cena, ou o lugar (que propunha Craig), torna-se um espaço privilegiado para nosso embate histórico, no campo da transformação dos indivíduos e suas subjetividades ou na transformação das coletividades e de nossas formas de organização social.

Nesse contexto, a proposição dos screens de Craig - em que a cena ganha amplitude arquitetônica, reincorporando seus aspectos sociais para além do quadro cênico fechado em si mesmo, e os atores se fazem quase ausentes enquanto operadores humanos, despidos de máscaras, "atuam" manipulando a própria cena, à vista do público - antecipa várias questões do nosso teatro do presente, em particular o questionamento do(s) regime(s) de representação (Ramos, 2017, p. 31); mas também reintegra uma aspiração a certa totalidade, herdada de nosso passado, ou ao menos do legado de uma imagem desse passado, propondo talvez novo(s) regimes representacionais, nos últimos respiros das aspirações iluministas, que nos parecem tão necessários nos atuais dias de tão profunda crise democrática. Basta pensarmos na presença dos diversos operadores de luz, quando as salas de espetáculo eram atulhadas de velas, lâmpadas de óleo, etc., que muitas vezes apagavam e precisavam ser acessas novamente ou simplesmente era necessário realizar essas ações para causar efeitos à cena; também não é novidade que a base de inspiração de Craig para seu 
projeto Cena foi a obra Architettura, escrita por Sebastiano Sérlio (1475-1554), importante arquiteto e cenógrafo renascentista (Grazioli, 2015, p. 160).

No caso da proposição dos screens, manipulados por atores/operadores, assentados em suas rodinhas, transformados pela iluminação controlada pela mais moderna tecnologia, Craig apresenta uma configuração em que passado e futuro, instalados em seu contexto presente, concretizam uma proposta cênica e estética que carrega algumas das sementes da cena moderna, como tentamos mostrar; e que se apresentará em vasta produção teatral no século XX. Tal proposição torna-se ainda mais interessante se pensarmos a probabilidade de que tal seja a configuração da maturação estética e das necessidades materiais (tecnológicas e econômicas) impostas a Craig pela experiência histórica concreta, no período da Primeira Guerra Mundial.

A cena do futuro, que os homens dos finais do século XIX e inícios do XX sonharam para nós, junto com a iluminação elétrica, essa "novidade", apresenta forte potencial transitivo entre o material e o imaterial, o real e o sonho, o passado e o futuro, o econômico e o estético, a indústria e os desejos, tornando-se assim, a proposição de uma cena que procurou colocar em xeque nossas concepções sobre o mundo e sobre nós, de dentro do próprio mundo, visando desestabilizá-lo numa aspiração a algo melhor. A tecnologia da luz elétrica iluminou uma cena em que, numa crítica aos nossos equívocos históricos (do passado, presente e até mesmo futuro), o não humano aspirou a ser mais que humano.

\section{Referências}

APPIA, Adolphe. A obra de arte viva. Trad. Redondo Júnior. Lisboa: Editora Arcádia, s.d.

BABLET, Denis. A luz no teatro. In: O teatro e sua estética. Trad. Redondo Júnior. Lisboa: Editora Arcádia, 1964.

BRECHT, Bertolt. A compra do latão. Trad. Urs Zuber. Lisboa: Veja, 1999.

BÜCHNER, Karl Georg. Leonce e Lena. In: GUINSBURG, Jacó; KOUDELA, Ingrid Dormien (Org.). Büchner: na pena e na cena. Trad. Jacó Guinsburg e Ingrid D. Koudela. São Paulo: Perspectiva, 2004.

CAMARGO, Roberto Abdelnur. Luz e cena: processos de comunicação coevolutivos. São Paulo, 2006. Tese (Doutorado) - Programa de Estudos Pós-graduados em Comunicação e Semiótica, Pontifícia Universidade Católica de São Paulo.

CAMARGO, Roberto Gil. A função estética da luz. 2 ed. São Paulo: Perspectiva, 2012.

CRAIG, Edward Gordon. Rumo a um novo teatro \& cena. Trad. Luiz Fernando Ramos. São Paulo: Perspectiva, 2017. 
CRAIG. Da arte do teatro. Trad. Redondo Júnior. Lisboa: Editora Arcádia, 1963. DORT, Bernard. O teatro e sua realidade. Trad. Fernando Peixoto. São Paulo: Perspectiva, 1977.

FORJAZ, Cibele. À luz da linguagem: a iluminação cênica: de instrumento da visibilidade à 'scriptura do visível' \& outras poéticas da luz. São Paulo, 2013. Tese (Doutorado) - Escola de Comunicações e Artes, Universidade de São Paulo.

FORJAZ, Cibele. À luz da linguagem: a iluminação cênica: de instrumento da visibilidade à 'scriptura do visível' (primeiro recorte: do fogo à revolução teatral). São Paulo, 2008. Dissertação (Mestrado) - Escola de Comunicações e Artes, Universidade de São Paulo.

GRAZIOLI, Cristina. Pontos críticos e equilíbrios dinâmicos: estudar a História do Teatro de Figura. Moin Moin, revista de estudos sobre teatro de formas animadas. Ano 12, número 16, p. 17-39, 2016. Disponível em: http://www.udesc.br/arquivos/ceart/ id_cpmenu/2645/revista_moin_moin_16_15002287209367_2645.pdf. Acesso em: 7 ago. 2017.

GRAZIOLI. Luce e ombra: storia, teorie e pratiche dell'illuminazione teatrale. Roma-Bari, Laterza, 2008.

MARINETTI, F. T. “Manifesto Futurista - 1909”, s.d. Disponível em: https://memoriavirtual.net/2005/02/21/futurismo-manifesto-futurista-2/. Acesso em: 25 maio 2017.

NOSELLA, Berilo L. D. Inacabamento, um gesto de resistência na história: a metateatralidade de Luigi Pirandello e Jorge Andrade. Vitória: Cousa, 2014.

RABETTI, Maria de Lourdes (Beti Rabetti). Teatro e comicidades: estudos sobre Ariano Suassuna e outros ensaios. Rio de Janeiro: 7Letras, 2005.

RABETTI. Teatro e comicidades 2: modos de produção do teatro ligeiro carioca. Rio de Janeiro: 7Letras, 2007.

RAMOS, Luiz Fernando. Gordon Craig: inventor da cena moderna. In: CRAIG, Edward Gordon. Rumo a um novo teatro \& cena. Trad. Luiz Fernando Ramos. São Paulo: Perspectiva, 2017.

ROUBINE, Jean-Jacques. A linguagem da encenação teatral, 1880-1980. Trad. Yan Michalski. 2 ed. Rio de Janeiro: Jorge Zahar, 1998.

SARAIVA, Hamilton Figueiredo. Interações físicas e psíquicas geradas pelas cores na iluminação teatral. São Paulo, 1999. Tese (Doutorado) - Escola de Comunicações e 
Artes, Universidade de São Paulo.

SARAIVA. Iluminação teatral: história, estética e técnica. São Paulo, 1989. Dissertação (Mestrado) - Escola de Comunicações e Artes, Universidade de São Paulo.

TUDELLA, Eduardo A. da Silva. Práxis cênica como articulação de visualidade: a luz na gênese do espetáculo. Salvador, 2013. Tese (Doutorado) - Escola de Teatro, Universidade Federal da Bahia.

Recebido em: $27 / 11 / 2017$ Aprovado em: 08/02/2018 